\section{Uma incursão \\ pela poética \\ medieval}

EDITH PIMENTEL PINTO

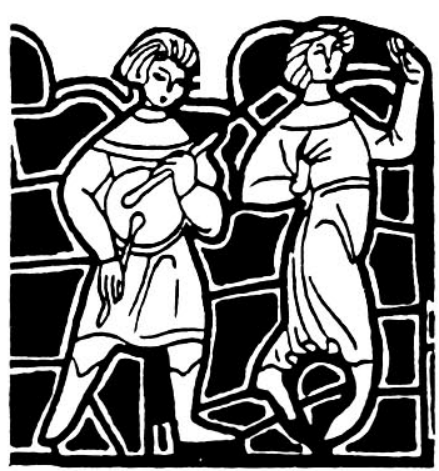

EDITH PIMENTEL PINTO é professora da FFLCH-USP e autora, entre outros, de $A$ Gramatiquinha de Mário de Andrade - Texto e Contexto (Duas Cidades).

A Lfrica Trovadoresca, Segismundo Spina, Sâo Paulo, Edusp, $414 \mathrm{pp}$.
A Lírica Trovadoresca, que inaugura a nova coleção “Texto e Arte", é, por todos os
títulos, um lançamento importante. Tanto gráfica quanto intelectualmente considerado, ê um trabalho relevante, capaz de interessar a estudiosos de vários tipos, desde o filologo ao músico ou o bibliófilo, graças ao rico e variado material que põe à disposição de um público já desacostumado a tais requintes de aprimoramento.

Seu autor, o professor Segismundo Spina, é entre nós, atualmente, talvez o único medievalista e certamente o único capacitado a produzir obra semelhante. Credenciamno vários estudos que, no correr de seu longo trato com a matéria, desenvolveu e aprimorou, alguns deles marcos de sua brilhante carreira como filologo e professor de Língua e Literatura Portuguesa na USP.

A primeira edição da obra recém-lançada intitulava-se Apresentaçâo da Lírica Trovadoresca $^{(1)}$ e esboçava já um panorama do movimento poético que, da Provença, se irradiou por grande parte da Europa, nos séculos XII, XIII e XIV. Bem acolhido pela crítica, o trabalho mereceu atenção especial de alguns intelectuais, como Súlvio Júlio, ao qual se deve uma sugestão que o autor acolheria nas edições seguintes: a inclusão de um capítulo sobre os goliardos, que não eram trovadores, mas jograis, os clérigos vagantes, que poetavam em latim e produziam textos líricos e satíricos em linguagem marcadamente obscena.

Acolhendo a sugestão, o Autor julgou necessário justificar a presença do novo capítulo, explicitando sua pertinência, "não pelos elementos genéticos (...), mas porque a produção goliárdica até certo ponto se confunde, no tempo e no espaço, com a poesia occitânica",(2).

Não obstante essa ressalva, o Autor identifica os elos expressionais dessa produção com a do trovadorismo, equacionando-a, assim, no âmbito do movimento lírico da época - e, conseqüentemente, justificando sua inclusão no plano do estudo: "A poesia dos vagantes trouxe, não há dúvida, uma contribuição preciosa para a formação do lirismo occitânico, especialmente da lírica alemã, mas não estamos em condições de afirmar que tenha sido a sua fonte (grifo do Autor). Na poesia dos goliardos encontram-se inúmeros temas, motivos e recursos imagéticos que constituem boa parte da espiritualidade poética trovadoresca",(3).

Nesta terceira edição, o Autor sustenta as mesmas posições sobre esse e outros pontos teóricos; e ainda as enriquece com novas citações e referências bibliográficas atualizadas. Mantém-se, igualmente, o roteiro da exposição, que se abre com um estudo minucioso e erudito do movimento trovadoresco, cuja amplitude se concretiza no mapa relativo à sua fase de esplendor(4).

Segue-se a essa parte teórica um estudo de textos, dispostos em ordem cronológica e por localização geográfica.

Cada texto dessa antologia, selecionado por sua representatividade, vem traduzido em prosa, pois o Autor confessa que "não tem pretensões literárias", mas sim "a preocupação pela fidelidade ao espírito do texto"(5).

Encerra cada um desses estudos com um comentário, sempre precioso para a boa in-

\footnotetext{
1 Rio de Janeiro, Acadermica, 1956.

2 A Lirica Trovadoresca, $2^{\mathrm{a}}$ ed., Săo Paulo/Rio de Janeiro, Grifo/Édusp, 1972 , p. 16.

3 Idem, ibidem, p. 30 .

4 Idem, ibidem, p. 85.

5 Idem, ibidem, p. 12.
} 


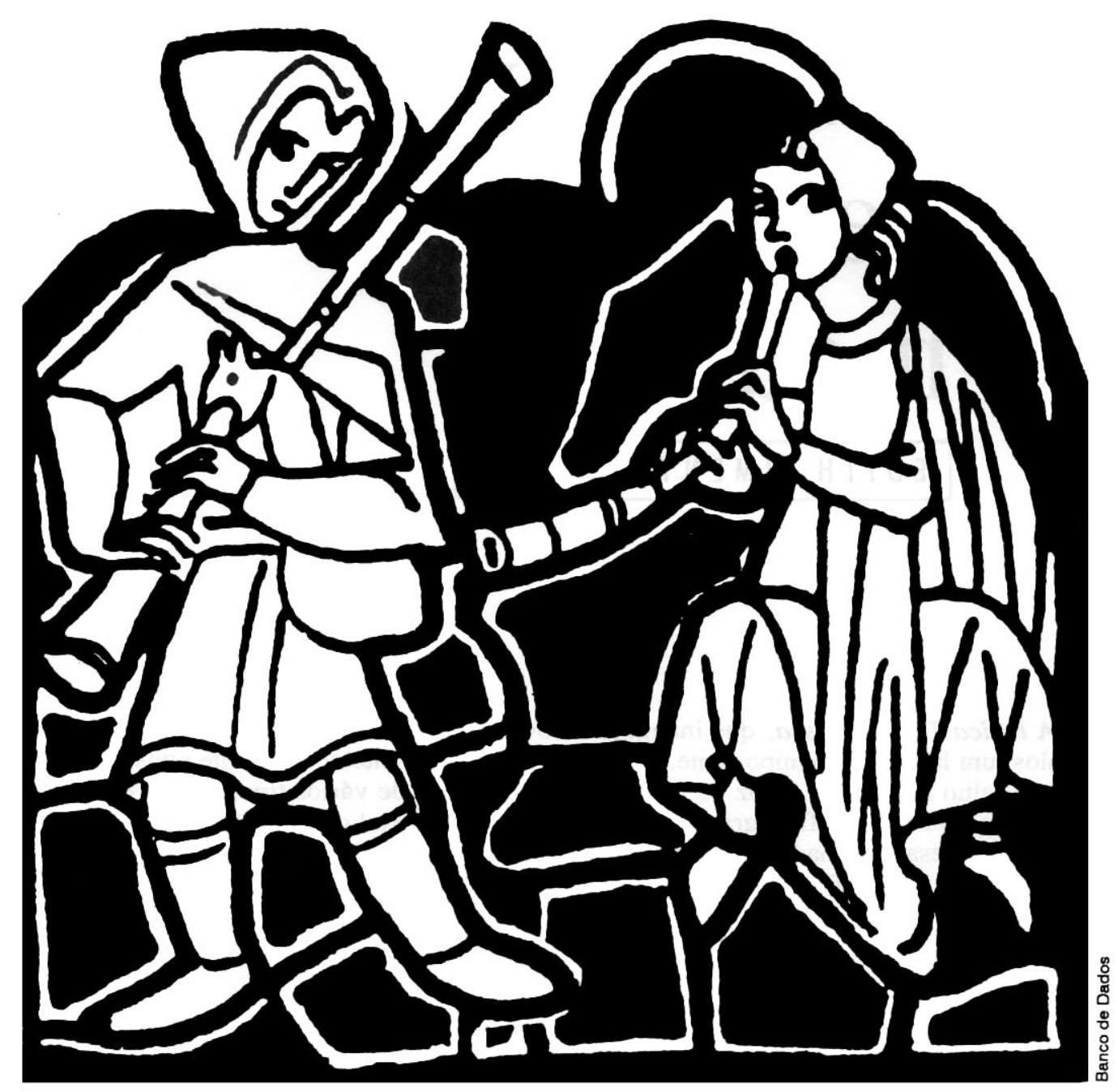

Trovadores numa miniatura medieval

terpretação do texto e sua inserção no movimento poético geral europeu e particular da região. Para esse fim se avançam esclarecimentos sobre a figura de cada autor e sua circunstância, além de informações pertinentes a pontos específicos da composição poética, quando é o caso.

Completam o volume dois apêndices: um sobre árabe, que "se aproxima do conteúdo do espírito cortês da lírica românica"(6); outro, nesta edição expandido e ocasionalmente retificado, constitui-se de um "Glossário Terminológico", que o Autor oferece como núcleo para "elaboração mais amplas"(7) que se fazem sempre urgentes, pois se trata de uma lacuna que deixa ao desamparo os interessados nesse ramo de estudo e desestimula as vocações nascentes.

Somados, a introdução teórica, a tradução, os comentários filológicos e o glossário compõem um material de primeira ordem, onde se encontram todas as chaves para uma incursão proveitosa pelo mundo poético medieval, alêm de indicações bibliográficas indispensáveis para qualquer pesquisa nesse campo de interesse.

Para inserir-se no plano editorial que inaugura, esta terceira edição de $A$ Ltrica Trovadoresca apresenta-se graficamente enriquecida com farto material iconográfico, constitufdo de ilustrações várias e, sobretudo, de fac-símiles de páginas de manuscritos, de capas, frontispícios e excertos de livros - inclusive pautas musicais -, material quase todo praticamente inacessível, mesmo a um leitor qualificado.

Esta breve notícia daquela que talvez seja a obra-prima dentre a produção do professor Segismundo Spina, embora não dê conta de todas as suas excelências, pretende enfatizar-lhe a importância no plano específico dos estudos a que pertence, assim como realçar sua significação para a cultura brasileira, ultimamente tão empobrecida. 